\title{
Workplace violence against nurses at Minia district hospitals
}

\author{
Ebtesam Esmail Hassan ${ }^{*}$ Naglaa Mohammed Amein², Sanaa Mohmoud Ahmed³
}

'Department of Public Health and Preventive Medicine, Faculty of Medicine, Minia University, Minia, Egypt, ${ }^{2}$ Department of Community Health Nursing, Faculty of Nursing, Minia University, Minia, Egypt, ${ }^{3}$ Department of Pediatric Nursing, Faculty of Nursing, Minia University, Minia, Egypt

\begin{abstract}
Introduction: Violence against nurses at the workplace is an alarming problem in both developed and developing countries affecting the quality of their work. The aim of this study is to assess the prevalence of external (patient initiated) and internal violence (initiated by staff members) against nurses and studying the violence-associated factors such as perpetrators, the attitude of nurses following aggression incidents, consequences, and impact on nurses and work.

Methods: A cross-sectional study included 385 nurses from three different hospitals in Minia district was agreed to participate in the study. These hospitals included Health Insurance Hospital, Minia University Hospitals (Minia University Gynecological, Obstetric, and Pediatric Hospital and Minia Renal Hospital), and Minia general hospital. The well-structured questionnaire covered four main domains; sociodemographics, lifetime working experience of violence, external and internal violence and its effects on work, the perpetrators of violence, and attitude of nurses following violent incidents.
\end{abstract}

Results: More than half of nurses (55.8\%) were exposed to workplace violence during their working lifetime. Experiencing external violence (patient initiated) during the past year was significantly higher $(57.4 \%)$ than the internal (staff initiated) type (33.5\%). Verbal violence was the most common type of violence. Reporting violence incidents were done by $68.3 \%$ and $38.7 \%$ of the nurses who were exposed to external and internal violence, respectively.

Conclusion: Violence against nurses working in different health-care facilities at Minia district was prevalent and has a significant impact on nurses and their work.

Keywords: Workplace violence; against nurses; Minia; Egypt

\section{INTRODUCTION}

Violence against health care workers is highly prevalent, the World Health Organization (WHO)

\footnotetext{
*Corresponding author: Ebtesam Esmail Hassan, Department of Public Health and Preventive Medicine, Faculty of Medicine, Minia University, Minia, Egypt. E-mail: eptesamamar@yahoo.com
}

Submitted: 04 January 2020/Accepted: 19 March 2020 defines the workplace violence that the staffs are abused, threatened, or assaulted in circumstances related to their work (1). Workplace violence against nurses has significantly increased in the past decade or so, with some studies suggesting $110 \%$ spike in the rate of violent injuries against health care workers in the past 10 years. According to the National Institute for Occupational Safety and Health, there are four types of workplace violence in the healthcare field. Type I: The perpetrator has criminal 
intent and has no relationship to the business or its employees. Type II: A customer, client, or patient becomes violent when receiving care or services. Type III: Employee-to-employee violence. Type IV: Personal relationship violence (2). Workplace violence considered an endemic problem in health care $(6,18)$ and nurses are considered at a higher risk of abuse $(3,4.5)$. Nearly one-quarter of the world's workplace violence occurs in that sector (6). The WHO defines workplace violence as, "Incidents where the staff is abused, threatened, or assaulted in circumstances related to their work, including commuting to and from work, involving an explicit or implicit challenge to their safety, well-being, or health.” The WHO considers both physical and psychological harm, including attacks, verbal abuse, bullying, and both sexual and racial harassment, to be workplace violence (7). Health workers are at high risk of violence all over the world. Between $8 \%$ and $38 \%$ of health workers suffer physical violence at some point in their careers. Many more are threatened or exposed to verbal aggression. Most violence is perpetrated by patients and visitors. Furthermore, in disaster and conflict situations, health workers may become the targets of collective or political violence. Categories of health workers most at risk include nurses and other staff directly involved in patient care, emergency room staff, and paramedics (7). Nurses are most available personnel in the hospital exposed to stressful situations such as accidents, deaths, waiting to visit a physician, or transfer of patients to a ward or another hospital, these situations expose them to more abuse from patients or their relatives besides the verbal and non-verbal aggression, they sometimes face from hospital staff (9). During the professional lifetime, half of health care workers experience at least one incident of physical or psychological violence, violence rate among nurses reported to be as high as $75.8 \%$ in Bulgaria, 67.2\% in Australia, 61\% in South Africa, $37 \%$ in Portugal, $54.0 \%$ in Thailand, and $46.7 \%$ in Brazil (10). Regarding different forms of violence against nurses, the physical abuse represents about one-third while the sexual ones represent one-quarter and about two-thirds are verbally and emotionally assaulted, in the Middle East; non-physical was the highest, whereas the USA and Europe are particularly prone to violence of all types including even sexual harassment. The most common perpetrators of violence against nurses were found to be patients' family and friends (9). In Lower Egypt, the prevalence rates of violence against nurses that were detected by two studies showed marked discrepancies; $86.1 \%$ in Cairo University (11) and $27 \%$ in Ismailiya (1). In Upper Egypt, a study was conducted in BeniSuef and found that $92.8 \%$ of BeniSuef nurses were exposed to workplace violence at least once during their working lifetime (9). The study aims to assess the prevalence of external (patient initiated) and internal violence (initiated by staff members) against nurses and studying the violence-associated factors such as perpetrators, an attitude of nurses following aggression incidents, consequences, and impact on nurses and work.

\section{METHODS}

A cross-sectional study was conducted during the period from August 2016 to December 2016. A convenience sample was used and 385 nurses from three different hospitals in Minia district were agreed to participate in the study. These hospitals included Health Insurance Hospital, Minia University Hospitals (Minia University Gynecological, Obstetric and Pediatric Hospital and Minia Renal Hospital), and Minia general hospital. Face-to-face interviewing was used for data collection. Finally, the questionnaire was designed to cover four main domains; sociodemographics of the surveyed nurses, lifetime working experience with aggression, external aggression and its effects on work and emotional consequences, and internal aggression and its impacts on work. We also focused on the perpetrators and attitude of nurses following aggression incidents. The questionnaire included also a variety of pre-defined response options, including questions that asked respondents to check the frequency of the occurrence of violence, once, 2-5 times, 6-10 times, or $>10$ times (2). The study was approved by the Ethical Committee of the Faculty of Medicine, Minia University. Before data collection, official permissions were obtained from the authorities of Minia district hospitals. Following the ethical guidelines of epidemiological research, written informed consent was taken from each participant. A full explanation about the research 
objectives to the interviewees and their willingness to participate in this study, keeping confidentiality, and personal interview in a private place was among these commitments. Data were analyzed using the software, Statistical Package for the Social Sciences (SPSS) version 19. Qualitative data were presented as frequency distribution and quantitative data were presented as mean and standard deviation. Chisquare and $\mathrm{Z}$ tests were done. $p<0.05$ was considered as a cutoff for significance.

\section{RESULTS}

The majority of the studied nurses were women $(87.3 \%)$ and men represent $12.7 \%$. Their ages ranged from 19 to 38 years, with a mean of 27.7 \pm 5.4 years. Approximately $50 \%$ of the participants were married and $2.6 \%$ were divorced. Only a small proportion $(1.3 \%)$ of the sample had less than secondary or more than a university degree $(1.3 \%)$, whereas almost half $(50.6 \%)$ possessed a bachelor's degree in nursing. The mean experience of working was $1.8 \pm 1.3$, with the category of $1-5$ years which is the most prevalent $(83.9 \%)$ (Table 1$)$.

Table 2 shows that more than half of nurses (55.8\%) were exposed to workplace violence during their working lifetime, of which $50.9 \%$ faced violence twice to fifth times. Experiencing external violence during the past year was significantly higher (57.4\%) than the internal type (33.5\%), and 59.7\% and $83.7 \%$ of those who experienced external and internal violence, respectively, faced it twice to fifth times (Table 2).

Verbal violence was the most common type of violence that nurses were exposed to during their life, reaching about $52.6 \%$, followed by sexual type $18.1 \%$, psychological $17.7 \%$, and finally, physical assaults $11.6 \%$.

During the past year, the most common reported external aggression was the verbal type representing more than two-thirds (72.4\%), followed by psychological (15.8\%), sexual (4.5\%), and finally physical (2.3\%). About $82.2 \%$ of the reported internal violence incidents for nurses were of the verbal type, $15.5 \%$ for psychological aggression, $1.6 \%$ for sexual aggression, and $0.8 \%$ for physical aggression.

Reporting violence incidents were done by $68.3 \%$ and $38.7 \%$ of the nurses who were exposed to
TABLE 1. Distribution of the studied nurses according to their demographic and professional characteristics, Minia district hospitals

\begin{tabular}{lc}
\hline Data & Total=385 \\
\hline Age & $19-38$ \\
Range & $27.7 \pm 5.4$ \\
Mean \pm SD & \\
Sex & $49(12.7 \%)$ \\
Male & $336(87.3 \%)$ \\
Female & \\
Residence & $138(35.8 \%)$ \\
Urban & $247(64.2 \%)$ \\
Rural & \\
Marital status & $190(49.4 \%)$ \\
Single & $185(48.1 \%)$ \\
Married & $10(2.6 \%)$ \\
Divorced & \\
Education & $5(1.3 \%)$ \\
Less than secondary & $180(46.8 \%)$ \\
Secondary & $195(50.6 \%)$ \\
University & $5(1.3 \%)$ \\
More than university & $60(15.6 \%)$ \\
Day shift & $26(6.8 \%)$ \\
Mid shift & $299(77.7 \%)$ \\
Night shift & $62(16.1 \%)$ \\
$<1$ year & $323(83.9 \%)$ \\
1-5 years &
\end{tabular}

external and internal violence, respectively. Nurses who were exposed to external violence reported their incidents to the administration (36.4\%), security (27.2\%), or physician (23.2\%), and colleagues and relatives $(13.2 \%)$; whereas, nurses who faced internal violence reported the incidents to the administration $(68 \%)$, security (14\%), and colleagues and relatives $(18 \%),(p=0.003)$. Regarding causes none reporting, $72.8 \%$ and $63.3 \%$ of nurses exposed to external and internal violence report that there was no effect from reporting (Table 3).

Table 4 shows that males were the most common perpetrators of the violent incidents against nurses $(62.4 \%$ for external and $76 \%$ for internal types). Patient's relatives were the perpetrators who committed the incidents of external violence against a nurse. Supervisors (58.1\%), colleagues $(34.1 \%)$, and administrative staff (7.8\%) were the reported perpetrators who committed internal violence against nurses (Table 4). 
TABLE 2. Prevalence of lifetime exposure to violence prevalence, external and internal violence against nurses during the past year, Minia district hospitals

\begin{tabular}{lcccc}
\hline Data & Lifetime exposure violence against nurse & \multicolumn{3}{c}{ Last 12 months } \\
\cline { 3 - 4 } & & $221(57.4)$ & $129(33.5)$ & $\mathrm{Z}=4.3$ \\
\cline { 3 - 4 } & & & & Exposure to violence \\
& & & & \multicolumn{3}{c}{ External } & Internal & $007^{*}$ \\
Prevalence (no. 385) (\%) & & 221 & 129 & $X^{2}=20.6$ \\
Frequency & 215 & $89(40.3)$ & $21(16.3)$ & $p=0.005^{*}$ \\
Once (\%) & $84(39.1)$ & $132(59.7)$ & $108(83.7)$ & \\
Twice to fifth (\%) & $131(50.9)$ & 221 & 129 & $X^{2}=10.6$ \\
Type & 215 & $5(2.3)$ & $1(0.8)$ & $p=0.03^{*}$ \\
Physical (\%) & $25(11.6)$ & $160(72.4)$ & $106(82.2)$ & \\
Verbal (\%) & $113(52.6)$ & $35(15.8)$ & $20(15.5)$ & \\
Psychological (\%) & $38(17.7)$ & $10(4.5)$ & $2(1.6)$ & \\
Sexual (\%) & $39(18.1)$ & $11(5)$ & 0 & \\
More than one type (\%) & 0 & &
\end{tabular}

A comparison was done between external and internal violence

TABLE 3. Frequency of reporting of external and internal violence against nurses and causes of non-reporting, Minia district hospitals

\begin{tabular}{lccc}
\hline Reporting & External no. 221 (\%) & Internal no.129 (\%) & $p$ \\
\hline Reporting & $151(68.3)$ & $50(38.7)$ & $\begin{array}{c}\mathrm{Z}=3.7 \\
p=0.008^{*}\end{array}$ \\
Reported to & & & $X^{2}=23.3$ \\
Administrator & 151 & 50 & $p=0.003^{*}$ \\
Security & $55(36.4)$ & $34(68)$ & \\
Physician & $41(27.2)$ & $7(14)$ & \\
Relatives and friends & $35(23.2)$ & 0 & $X^{2}=2.8$ \\
Cause of non-reporting & $20(13.2)$ & $79(18)$ & $p=0.2$ \\
Fit the situation from the periphery & $70(31.4)$ & $20(25.3)$ & \\
Apology of the aggressor & $10(14.2)$ & $9(11.4)$ & \\
Reporting has no effect & $9(12.8)$ & $50(63.3)$ & \\
\hline
\end{tabular}

TABLE 4. Sociodemographic characters of violence perpetrators against nurses, Minia district hospitals

\begin{tabular}{lcc}
\hline $\begin{array}{l}\text { Characters of violence } \\
\text { perpetrators }\end{array}$ & External no. 221 & Internal no.129 \\
\hline Age & $35.7 \pm 10.4$ & $32.1 \pm 7.4$ \\
Sex & & \\
$\quad$ Male (\%) & $138(62.4)$ & $98(76)$ \\
$\quad$ Female (\%) & $83(37.6)$ & $31(24)$ \\
Who & & \\
$\quad$ Administrator (\%) & 0 & $10(7.8)$ \\
Colleagues (\%) & 0 & $44(34.1)$ \\
Nurse supervisor (\%) & 0 & $75(58.1)$ \\
Patient relative (\%) & $221(100)$ & 0 \\
\hline
\end{tabular}

The most reported consequences of external violence by exposed nurses were anger $(32.1 \%)$, whereas no effect represented by $28.6 \%$ of exposure to internal type. Regarding the impact of exposure to violence on work performance, of the nurses who faced external and internal aggression last year, 38.5\% and $45.7 \%$ reported that their work has not been affected by the violence incidents; however, $61.4 \%$ and $54.5 \%$, respectively, reported that exposure to violence incidents affected their work in various levels; about $23.1 \%$ of nurses who experienced external violence reported being not satisfied with the job, bored of work, $18.6 \%$ of nurses who experienced 
internal violence reported decreased interest and efficiency at work (Table 5).

\section{DISCUSSION}

The prevalence results showed that $55.8 \%$ of Minia nurses were exposed to workplace violence during their working life and during the past year, $57.4 \%$ and $33.5 \%$ of them experienced external "patient initiated" and internal violence "staff-initiated violence" (Table 2). This is similar what found in Canadian hospitals in Alberta and British Columbia, nearly half of those surveyed had experienced one or more types of violence in the past five shifts worked (11) and these findings were lower than the study of workplace violence against nurses in Benisuef and found that the majority of their nurses $(92.8 \%)$ had been exposed to violence at work (9), and the finding of Iranian studied violence against nurses: A neglected and health-threatening epidemic in the university-affiliated public hospitals in Shiraz, Iran, and found that $89.6 \%$ of nurses had experienced at least one kind of violence (14). The finding of the current study was higher what found in Ismailia governorate, Egypt, and determined its prevalence to be about $27 \%$ (2). The reasons for such differences are referred to as the different methodologies of different studies, especially inquiring about violent incidents in various periods of work.
Verbal violence was the most common type of violence that nurses were exposed to, reaching about $52.6 \%$, followed by sexual aggression $18.1 \%$, psychological $17.7 \%$, and finally physical assaults $11.6 \%$, these findings support the finding of Beniswef study which found that verbal and psychological violence incidents were the most common types of violence that nurses were exposed to, reaching about $97.6 \%$ and $74.6 \%$, respectively, followed by physical aggression $33.4 \%$ and finally sexual assaults 19.8\% (9). Psychological violence was the most common form (78.1\%) of workplace violence against a nurse in Cairo hospitals, Egypt (12). Health care workers in Palestinian public hospitals have a higher rate of exposure to non-physical violence $(59.6 \%)$ followed by physical violence (20\%) (13). Furthermore, in Hong Kong, it was reported that the most prevalent violence was verbal abuse (73\%) followed by physical and sexual abuse (14). Regarding the type of workplace violence in Iran, the highest proportion of abuse was in verbal nature (10). In the present external and internal violence incidents were done by $68.3 \%$ and $38.7 \%$ of the nurses respectively, external and internal violence incidents were reported to administration by $36.4 \%$ and $68 \%$ of nurses exposed to, respectively (Table 3), these results were in agreement with the study in Ghana and found that $(35.8 \%)$ of violence

TABLE 5. Consequences of violence on nurses and its impact at work, Minia district hospitals

\begin{tabular}{lcc}
\hline Consequences of violence & External no. 221 (\%) & Internal no.129 (\%) \\
\hline No effect & $70(31.7)$ & $37(28.6)$ \\
Fear & $10(4.5)$ & $5(3.9)$ \\
Anger & $71(32.1)$ & $34(24.5)$ \\
Stress & $36(16.3)$ & $32(24.8)$ \\
Humiliation feeling & $15(6.8)$ & $7(5.4)$ \\
Depression & $14(6.3)$ & $1(0.8)$ \\
Guilty sensation & $4(1.8)$ & $4(3.1)$ \\
Desire to leave work & $9(4.1)$ & $5(3.9)$ \\
Desire to take revenge & 0 & $4(3.1)$ \\
Impact at work & & \\
No impact & $85(38.5)$ & $59(45.7)$ \\
Not satisfied and pored & $51(23.1)$ & $13(10.1)$ \\
Decreased interest and efficiency at work & $5(2.3)$ & $24(18.6)$ \\
Stressed job & $19(8.6)$ & $23(17.8)$ \\
Humiliation feeling at work & $15(6.8)$ & 0 \\
No right and lost justice & $33(14.3)$ & $10(7.8)$ \\
Feeling fear at work & $13(5.8)$ & 0 \\
\hline
\end{tabular}


incidents was reporting to a senior staff member, followed by telling a colleague about the incident $(32.1 \%)$ and then taking no action (18.8\%) (15). These findings approximate what found in Benisuef in which $56.4 \%$ and $47.1 \%$ of the nurses who were exposed to external and internal violence, respectively (8), and prevalence of violence against nurses in Ethiopia found that $48.2 \%$ of them report their violence (2). Underreporting tendencies might vary across world regions, and violence among nurses is frequently underreported, at least officially (16). The Middle Eastern women would be quite hesitant to admit to sexual harassment (17). Perpetrators who committed most of the external and internal violence incidents against nurses were males. Patients' relatives were the perpetrators who committed the incidents of external violence against a nurse. Supervisors (58.1\%), colleagues (34.1\%), and administrative staff $(7.8 \%)$ were the reported perpetrators who committed internal violence against nurses (Table 4). The previous studies reported that patient and their relatives were the most frequent propagators of violence against nurses (2). More than half $(58.5 \%)$ of violence preparators were patients' relatives $(15,19)$. Aligned with our findings, an Australian study, representative of Jordan nurses found that patients and their relatives were the most frequent propagators of verbal and physical violence (19). The most reported consequences by exposed nurses after being exposed to external violence were anger $(32.1 \%)$, whereas nurses who were exposed to internal violence reported no effect (28.6\%) (Table 5). Consequences and reactions of nurses after being exposed to external or internal violence incidents are various including; stress, anger, fear, depression, humiliation, lost rights, and injustice, almost one-third of the sample had an angry reaction (8). About $61.4 \%$ and $54.5 \%$ of nurses who experienced external and internal violence, respectively, reported that exposure to violence incidents affected their work at various levels (Table 5). The majority of nurses $(87.2 \%)$ who were exposed to violence believed that workplace violence had a negative effect on their work (19).

\section{CONCLUSION}

The results of this study revealed that violence against nurses working in different health-care facilities at
Minia district was prevalent and the patient-initiated type was the highly prevalent type. Safety training programs for the prevention of violence and to help nurses to understand violence-related reasons and risk factors, warning signs, procedures for its avoidance, prevention and management, and reporting if it occurs should be established in the organization. Policies and legislation targeting violence acts should be instituted and developed, and a high percentage of nurses need training in violence management.

\section{REFERENCES}

1. Fute M, Mengesha Z, Wakgari N, Tessema G. High prevalence of workplace violence among nurses working at public health facilities in Southern Ethiopia. BMC Nurs 2015;14(9):1-5.

2. Abbas MA, Fiala LA, Abdel Rahman AG, Fahim AE. Epidemiology of workplace violence against nursing staff in Ismailia governorate. Egypt J Egypt Public Health Assoc 2010;85(1):29-43.

3. Abualrub R, Al-Asmar A. Physical violence in the workplace among Jordanian hospital nurses. J Transcult Nurs 2011;22(2):157-65.

https://doi.org/10.1177/1043659610395769.

4. Gacki-Smith J, Juarez A, Boyett L, Homeyer C, Robinson L, MacLean SL. Violence against nurses working in US emergency departments. J Nurs Adm 2009;39(7-8):340-9. https://doi.org/10.1097/nna.0b013e3181ae97db.

5. Joa T, Morken T. Violence towards personnel in out-of-hours primary care: A cross-sectional study. Scand J Prim Health Care 2012;30(1):55-60.

https://doi.org/10.3109/02813432.2012.651570.

6. Azodo, C, Ezeja E, Ehikhamenor, E. Occupational violence against dental professionals in Southern Nigeria. Afr Health Sci 2011;11(3):486-92.

7. World Health Organization. Violence against Health Workers. Framework Guidelines for Addressing Workplace Violence in the Health Sector. Geneva, Switzerland: International Labour Office, International Council of Nurses, World Health Organization; 2002. http://www.who.int/violence_injury_prevention/violence/activities/workplace/en. [Last accessed on 2019 May 03].

https://doi.org/10.1177/2165079918810669.

8. Ewis AA, Arafa AE, Violence against nurses. An epidemiological study for nurses in municipal, health insurance and university hospitals of Beni Suef governorate, Egypt. Egypt J Occup Med 2014;38:1-22.

https://doi.org/10.21608/ejom.2014.785.

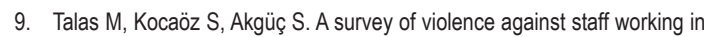
the emergency department in Ankara. Turk Asian Nurs Res 2011;5(4):197203. https://doi.org/10.1016/j.anr.2011.11.001.

10. Albashtawy M. Workplace violence against nurses in emergency departments in Jordan. International Nurs Rev. 2013;60(4):550-5.

https://doi.org/10.1111/inr.12059.

11. Shoghi M, Sanjari M, Shirazi F, Heidari S, Salemi S, Mirzabeigi G. Workplace violence and abuse against nurses in Hospitals in Iran. Asian Nurs Res 2008;2(3):185-92.https://doi.org/10.1016/s1976-1317(08)60042-0.

12. Hesketh $\mathrm{KL}$, Duncan SM, Estabrooks CA, Reimer MA, Giovannetti $P$, Hyndman $\mathrm{K}$, et al. Workplace violence in Alberta and British Columbia hospitals. Health Policy 2003;63(3):311-21.

https://doi.org/10.1016/s0168-8510(02)00142-2.

13. Samir N, Mohamed R, Moustafa E, Saif HA. Nurses' attitudes and reactions to workplace violence in obstetrics and gynecology departments in Cairo hospitals. East Mediterr Health J 2012;18(3):198-204. 
https://doi.org/10.26719/2012.18.3.198

14. Kitaneh M, Hamdan M. Workplace violence against physicians and nurses in Palestinian public hospitals: A cross-sectional study. BMC Health Serv Res 2012;12(469):1-8.https://doi.org/10.1186/1472-6963-12-469.

15. Kwak RP, Law YK, Li KE, Ng YC, Cheung MH, Fung VK, et al. Prevalence of workplace violence against nurses in Hong Kong. Hong Kong Med J 2006;12(1):6-9.

16. Boafo I, Hancock P. Workplace violence against nurses: A cross-sectional descriptive study of Ghanaian nurses. SAGE Open 2017; 7:1-9.

https://doi.org/10.1177/2158244017701187.
17. Snyder LA, Chen PY, Vacha-Haase T. The underreporting gap in aggressive incidents from geriatric patients against certified nursing assistants. Violence Vict 2007; 22(3):367-79. https://doi.org/10.1891/088667007780842784.

18. El-Gilany AH, El-Wehady A, Amr M. Violence against primary health care workers in Al-Hassa, Saudi Arabia. J Interpers Violence 2010;25:716-34. https://doi.org/10.1177/0886260509334395.

19. Samir N, Mohamed R, Moustafa E, Saif HA. Nurses' attitudes and reactions to workplace violence in obstetrics and gynecology departments in Cairo hospitals. East Mediterr Health J 2012;18(3):198-204.

https://doi.org/10.26719/2012.18.3.198. 